To be submitted to Ceram. Eng. Sci. Proc.

\title{
STRESS-RUPTURE OF NEW TYRANNO Si-C-O-Zr FIBER REINFORCED MINICOMPOSITES
}

\author{
Gregory N. Morscher * \\ Case Western Reserve University \\ Cleveland, Ohio
}

\begin{abstract}
Minicomposites consisting of two varieties of $\mathrm{Zr}$ containing SiC-based fibers from Ube (Tyranno) with $\mathrm{BN}$ interphases and CVI SiC matrices were studied. The two fiber-types were the $\mathrm{ZMI}$ and $\mathrm{ZE}$ fiber-types that contain approximately 8 and $2 \%$ oxygen, respectively. The minicomposites were precracked and tested under constant load testing at temperatures ranging from 700 to $1200^{\circ} \mathrm{C}$. The data were then compared to the rupture behavior of $\mathrm{Hi}-$ Nicalon ${ }^{\mathrm{TM}}$ fiber reinforced minicomposites tested under identical conditions. It was found that the Ube fiber-types had stress rupture life equivalent to $\mathrm{Hi}$ Nicalon $^{\mathrm{TM}}$ over the entire temperature range. A potential benefit of the ZMI fiber-type is that it offers rupture properties almost as good as Hi-Nicalon ${ }^{\mathrm{TM}}$ at the cost of ceramic grade Nicalon ${ }^{\mathrm{TM}}$.

\section{INTRODUCTION}

The polymer-derived Ceramic Grade Nicalon ${ }^{\mathrm{TM}}$ (NIC) [1] and HiNicalon ${ }^{\mathrm{TM}}(\mathrm{HN})$ [2] SiC-based fiber-types produced by Nippon Carbon are the most used and most mature commercially available SiC-based fiber-types. Processing of $\mathrm{HN}$ includes an irradiation curing step which reduces the oxygen content of this fiber $(\sim 1 \mathrm{w} / \mathrm{o} O)$ compared to NIC $(\sim 10 \% \mathrm{O})$. This results in a fiber that has greater thermal stability and improved creep resistance over NIC. Unfortunately, it also results in a significantly more expensive fiber.

The high temperature properties for constant-load tests of these fibers are now well known as well as the high temperature properties of many composite systems processed with these fibers. High temperature stress-rupture and creep testing have been reported for these fibers by Bodet et al. [3] and Yun and
\end{abstract}

\footnotetext{
- Resident research associate at NASA Lewis Research Center, MS 106-5, Cleveland, OH 44135; gmorscher@lerc.nasa.gov
} 
DiCarlo[4]. The rupture of single-tow minicomposites with these fibers has also been reported for various temperatures in air $[5,6]$.

More recently, SiC-based fibers [7] have been developed by Ube Industries which contain small amounts of $\mathrm{Zr}(1 \mathrm{w} / \mathrm{o})$ in the composition. These fibers have similar oxygen contents and SiC crystallite sizes for air-cured (ZMI: 8 w/o O) and irradiation cured (ZE: 2 w/o O) fibers compared to $\mathrm{NiC}$ and $\mathrm{HN}$, respectively. The high temperature strength and retained strength for fibers subjected to elevated temperature heat treatments were very good for both Ube fibers. This is especially surprising for the ZMI fiber since it contains a high oxygen-content which usually correlates with poor thermal stability properties.

However, little if any high temperature data has been reported for the fibers themselves or for composites processed with these fibers. In this study, single tows of $\mathrm{ZE}$ and $\mathrm{ZMI}$ fibers were coated with a boron nitride interphase and composited with a CVI SiC matrix to form minicomposites. The stress-rupture properties of the minicomposites were then determined at elevated temperatures in order to compare the rupture properties of these Ube fiber minicomposites with the Nippon fiber minicomposites tested in earlier studies $[5,6]$.

\section{EXPERIMENTAL}

Some properties of the Ube fibers used in this study as well as the Nippon Carbon fibers used in the other studies $[5,6]$ are listed in Table I.

Table I: Properties of Ube and Nippon Fibers from Product Literature

\begin{tabular}{|c|c|c|c|c|c|}
\hline Fiber & $\begin{array}{c}\text { Filaments } \\
\text { in tow }\end{array}$ & $\begin{array}{c}\text { Fiber } \\
\text { diameter, } \\
\mu \mathrm{m}\end{array}$ & $\begin{array}{c}\text { Elastic } \\
\text { Modulus, } \\
\text { Gpa }\end{array}$ & $\begin{array}{c}\text { Tensile } \\
\text { Strength, } \\
\mathrm{MPa}\end{array}$ & $\begin{array}{c}\text { Oxygen } \\
\text { Content, } \\
\text { w/o }\end{array}$ \\
\hline NIC & 250 & 14 & 210 & 3000 & 11.7 \\
\hline HN & 500 & 14 & 270 & 2800 & 0.5 \\
\hline ZMI & 800 & 13 & 210 & 3070 & 7.9 \\
\hline ZE & 400 & 13 & 234 & 3260 & 2.0 \\
\hline
\end{tabular}

Minicomposites were fabricated as described in an earlier study $[5,6]$. Boron nitride coating was performed on a continuous tow-coater at $1400^{\circ} \mathrm{C}$. The boron nitride coated at this temperature is more stable than $\mathrm{BN}$ coatings deposited at lower temperatures and will be referred to as PBN (pyrolytic BN). The coated tow was then wound on graphite racks and was infiltrated with CVI SiC ${ }^{* *}$ to form single-tow unidirectional minicomposites with a fiber volume fraction of $\sim 0.15$.

\footnotetext{
Advanced Ceramics Corporation, Lakewood, Ohio

* Hyper-Therm Inc., Huntington Beach California
} 
Several minicomposites were tensile tested to failure at room temperature in order to determine a sufficient load for precracking based on the non-linearity in the load-time curve and acoustic emission activity [8]. This load ranged from 70 to $85 \%$ of the ultimate load to failure for the minicomposites and corresponded to a matrix crack spacing on the order of $1 \mathrm{~mm}$.

Precracked minicomposites (gage length $\sim 150 \mathrm{~mm}$ ) were cold-gripped and dead-weight loaded. A $35 \mathrm{~mm}$ C-clamp SiC element resistance-heated furnace was inserted around the gage section. The hot zone of the furnace was $12 \mathrm{~mm}$ and the temperature profile of the furnace was well characterized. As in the earlier studies, tests were performed at 700,950 , and $1200^{\circ} \mathrm{C}$ (at the center of the hot zone).

\section{RESULTS}

The room temperature properties of the minicomposites are shown in Table II for the minicomposites tested in this study and in earlier studies. The failure stress determined in the table was determined by dividing the failure load by the cross-sectional area of the fibers in the tow. Note that all of the fiber strengths are greater than $2000 \mathrm{MPa}$ except for the ZMI-PBN minicomposites. For the NIC and $\mathrm{HN}$ minicomposite systems, the $\mathrm{BN}$ interphase was usually at least $0.4 \mu \mathrm{m}$ thick $[5,6]$. For the ZMI minicomposites, the exterior fibers had a 1 $\mu \mathrm{m}$ thick BN layer (Figure la), whereas the interior fibers had a $\sim 0.1 \mu \mathrm{m}$ thick $\mathrm{BN}$ layer (Figure 1b). ZE minicomposites had some similar thin interphase regions but not to the same extent as for $\mathrm{ZMI}$ minicomposites, probably because there were fewer fibers per tow for ZE (Table I). Pullout of ZMI and ZE fibers with thin interphases was usually less than a fiber diameter whereas pullout of ZMI and ZE fibers with thicker interphases was on the order of several hundred microns. The predominantly thin interphase for ZMI and ZE probably accounts for the poor ultimate strength properties of these minicomposite systems.

Table II: Room Temperature Minicomposite Strength Properties

\begin{tabular}{|c|c|c|c|}
\hline Minicomposite & $\begin{array}{c}\text { Number } \\
\text { Tested }\end{array}$ & $\begin{array}{c}\text { Avg. Failure Load, } \\
\text { N }\end{array}$ & $\begin{array}{c}\text { Avg. Failure Stress on Fibers } \\
\text { if Fully Loaded, MPa }\end{array}$ \\
\hline $\mathrm{ZE}-\mathrm{PBN}$ & 3 & $114 \pm 17$ & $2100 \pm 300$ \\
\hline $\mathrm{ZMI}-\mathrm{PBN}$ & 4 & $171 \pm 8$ & $1800 \pm 100$ \\
\hline $\mathrm{NIC}-3 \mathrm{MBN}^{\mathrm{b}}$ & 4 & $980 \pm 10$ & $2400 \pm 100$ \\
\hline $\mathrm{HN}-3 \mathrm{MBN}^{\mathrm{b}}$ & 4 & $140 \pm 10$ & $2100 \pm 100$ \\
\hline $\mathrm{HN}-\mathrm{PBN}$ & $\begin{array}{c}\text { Several } \\
\text { batches }^{\mathrm{a}}\end{array}$ & $140[5]$ to $186[6]$ & $2100[5]$ to $2750[6]$ \\
\hline
\end{tabular}

${ }^{a}$ The loads to failure and room temperature stress are for the widest range of values obtained from different batches of minicomposite. To date, four batches have been fabricated for this system and all fall in the range specified in Table II.

${ }^{b} \mathrm{BN}$ deposited at $\sim 1050^{\circ} \mathrm{C}$ by $3 \mathrm{M}$ Corporation, St. Paul Minnesota 


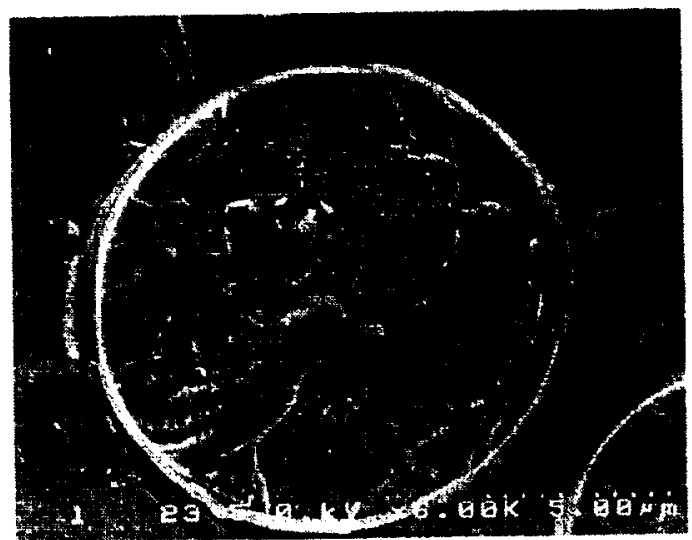

(a)

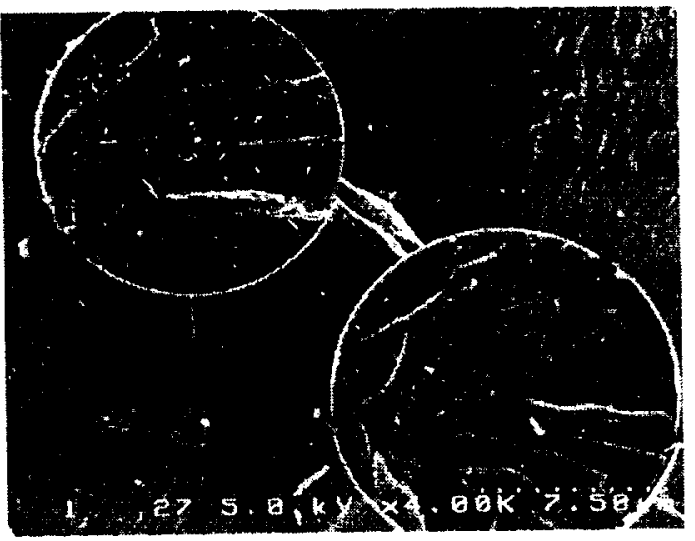

(b)

Figure 1: SEM micrographs of fibers from ZMI-PBN minicomposite after room temperature fracture. (a) is an exterior fiber and (b) are interior fibers. Note the thin interphase for the interior fibers.

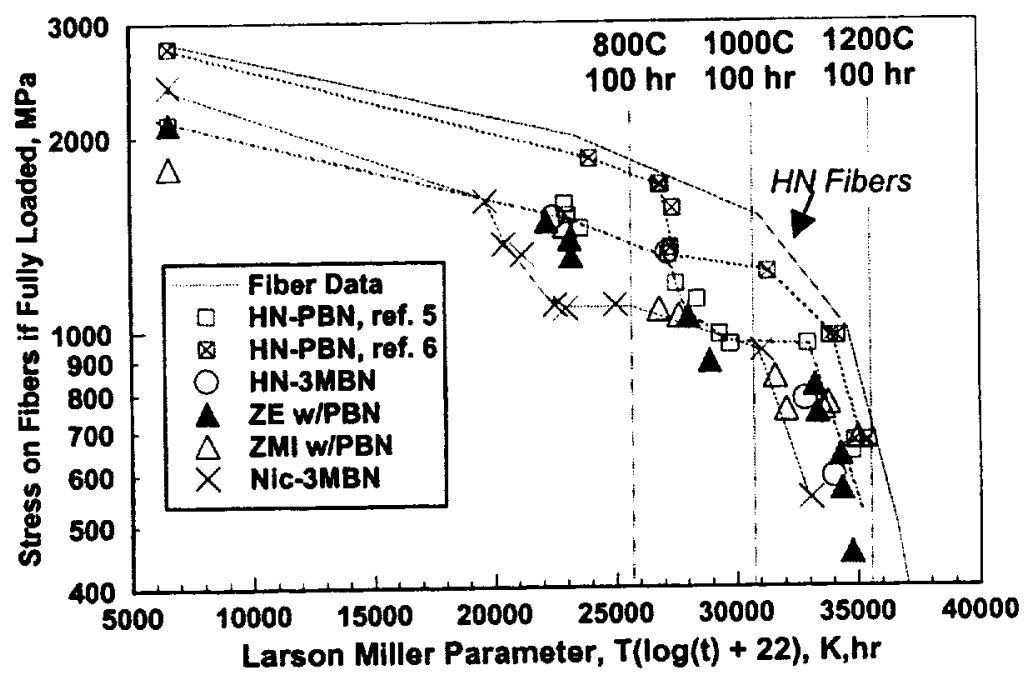

Figure 2: Absolute stress Larson-Miller plot of $\mathrm{SiC}$-fiber/BN interphase CVI$\mathrm{SiC}$ minicomposites.

The high temperature stress-rupture data are shown in Figures 2 and 3. The stress data is plotted versus a temperature compensated time "Larson-Miller" parameter. The Larson-Miller parameter was determined from the relationship: 


$$
\mathrm{LM}=\mathrm{T}[\log (\mathrm{t})+22]
$$

where $\mathrm{T}$ is the temperature in $\mathrm{K}$ and $\mathrm{t}$ is time in hours. This relationship was found to best fit the NIC and HN rupture data [4]. The actual "Larson-Miller" relationship has not yet been determined for the Ube fibers. However, the plots are used here for comparing all of the minicomposite rupture data and the rupture properties of as-produced HN and NIC on a single curve.

Figure 2 is a plot of the absolute stress on the fibers whereas Figure 3 is a plot of the normalized stress on the fibers. For HN-PBN, minicomposite strengths can vary for different batches (Table II). Figure 2 shows the two most extreme ultimate and rupture strengths for two different minicomposite batches over the entire temperature range $\left(25^{\circ} \mathrm{C}\right.$ to $\left.1200^{\circ} \mathrm{C}\right)$. However, the data normalized with room temperature ultimate strength are identical for the two different batches of HN-PBN (Figure 3). In addition, other data corresponding to a batch of minicomposites tested recently, "HN-PBN 1998", is plotted in Figure 3 which correlates well with the other HN-PBN data. Also plotted is HN-3MBN [5]. This minicomposite system consists of $\mathrm{HN}$ fibers fabricated with a lower processing temperature BN. Even though this BN was processed at lower temperatures little difference was observed in the rupture properties of this minicomposite system when tested in air. However, in higher water containing environments, significantly greater amounts of interphase oxidation and recession have been observed [9].

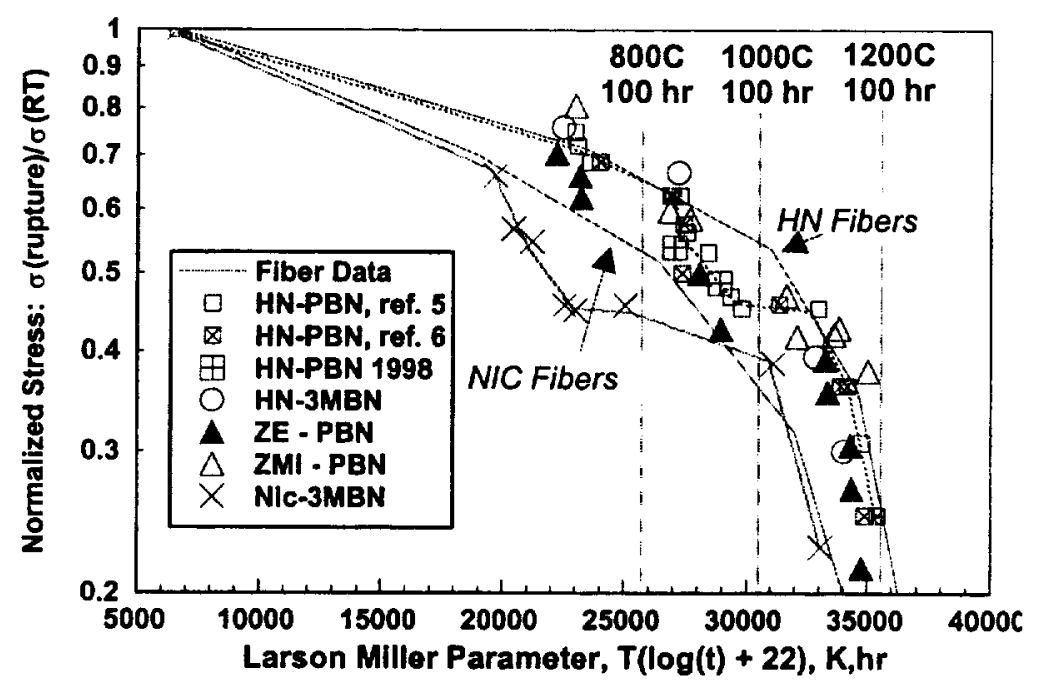

Figure 3: Normalized stress Larson-Miller plot of SiC-fiber/BN interohase CVI-SiC minicomoosites. 
At low $\left(<900^{\circ} \mathrm{C}\right)$ and high $\left(>1050^{\circ} \mathrm{C}\right)$ temperatures, the $\mathrm{HN}-\mathrm{BN}$ minicomposites show rupture behavior similar to the rupture of as-produced fibers. At intermediate temperatures $\left(1050^{\circ} \mathrm{C}>\mathrm{T}>900^{\circ} \mathrm{C}\right)$, the minicomposite rupture strengths fall below the as-produced fiber rupture strengths. This "embrittlement" was shown to be due to the oxidation of the interphase resulting in some weakening of the fibers and strong bonding of the fibers to the matrix $[5,6]$.

Also shown in Figures 2 and 3 are data from NIC-3MBN minicomposites $[5,8]$. The lower processing temperature interphase had to be used for NIC minicomposites because the NIC fibers were severely degraded after PBN coating. The NIC-3MBN minicomposites also show the same fiber-dominated rupture behavior at low $\left(<700^{\circ} \mathrm{C}\right)$ and high $\left(>1000^{\circ} \mathrm{C}\right)$ temperatures and an intermediate temperature decrease in the load carrying ability of the minicomposites compared to the as-produced fiber data (Figure 3). The rupture strengths of NIC fibers are lower than the HN fibers as can be seen in Figure 3.

The room temperature $\mathrm{ZE}$ minicomposite ultimate strengths correspond to the low range of HN minicomposite ultimate strengths. The ZMI ultimate strengths are below the $\mathrm{HN}$ and NIC minicomposite room temperature strengths. The high temperature data for ZE and ZMI minicomposites also fall in the low range or below the rupture strengths obtained for the $\mathrm{HN}$ minicomposites (Figure 2). However, the ZE and ZMI rupture data are better than the NIC minicomposite data at elevated temperatures even though the room temperature strengths are lower for ZE and ZMI minicomposites than for NIC minicomposites (Figure 2). When the ZMI and ZE minicomposite data are normalized with room temperature strength, the rupture behavior is nearly identical to the HN-PBN minicomposites and significantly better than the NIC-3MBN minicomposites (Figure 3).

It is evident that the $\mathrm{ZE}$ and $\mathrm{ZMI}$ minicomposites are performing as well as HN-PBN minicomposites for tensile rupture conditions in air. It would be expected that with thicker interphases, the ZMI minicomposite strengths would increase as well as the absolute rupture strengths. However, the normalized rupture strengths would be expected to remain the same as is the case for $\mathrm{HN}$ PBN minicomposites.

This result is not too surprising for ZE minicomposites since $\mathrm{ZE}$ fibers are processed similarly to $\mathrm{HN}$ fibers. The rupture behavior of ZMI minicomposites is somewhat surprising since this fiber-type contains a significant amount of oxygen. The claim that the thermal stability of ZMI is as good as ZE, and in this study HN as well, by Kumagawa et al [7] appears to be true not only for retained strength properties after heat treatment [7], but also for elevated temperature stress-rupture conditions as well.

The significance of this result is economic. At the time this report was written, the ZMI fiber-type was about one-fifth the price of ZE or HN fiber-types, 
i.e. about the same price as NIC. The savings that would be gained using the ZMI fiber-type in place of ZE or $\mathrm{HN}$ in the fabrication of a BN interphase composite with a CVI or melt-infiltrated $\mathrm{SiC}$ matrix could be as much as $50 \%{ }^{*}[10]$.

\section{CONCLUSION}

Minicomposites fabricated with the Zr-containing SiC fibers, ZMI and ZE, have the same elevated temperature stress-rupture properties as minicomposites fabricated with Hi-Nicalon ${ }^{\mathrm{TM}}$ fibers on a relative stress basis and significantly better stress-rupture properties than minicomposites fabricated with Nicalon ${ }^{\mathrm{TM}}$ fibers. Some improvement in rupture-strength and room temperature strength is expected if thicker interphase coatings were achieved for the ZMI and ZE minicomposites. The significance of this is that the ZMI fiber can be considered an inexpensive fiber choice, compared to $\mathrm{ZE}$ and Hi-Nicalon ${ }^{\mathrm{TM}}$, as the reinforcement for ceramic matrix composites aimed at higher temperature applications.

\section{ACKNOWLEDGEMENTS}

The author wishes to thank to Dr. Michiyuki Suzuki of Ube Industries for providing the ZMI and ZE minicomposites. The mechanical testing was performed at NASA Lewis Research Center under the HITEMP program.

\section{REFERENCES}

1. S. Yajima, J. Hayashi, M. Omori, and K. Okamura, "Development of a SiC Fibre with High Tensile Strength," Nature, 261, 683-685 (1976)

2. M. Takeda, Y. Imai, H. Ichikawa, T. Ishikawa, N. Kasai, T. Seguchi, and K. Okamura, "Thermomechanical Analysis of the Low Oxygen Silicon Carbide Fibers Derived from Polycarbosilane," Ceram. Eng. Sci. Proc., 14 (9-10), 540547 (1993)

3. R. Bodet, X. Bourrat, J. Lamon, and R. Naslain, "Tensile Creep Behavior of a Silicon Carbide-Based Fibre with a Low Oxygen Content," J. Mater. Sci., 30, 661-77 (1995).

4. H. M. Yun and J. A. DiCarlo, "Time/Temperature Dependent Tensile Strength of SiC and Al2O3-Based Fibers," in Ceramic Transactions, Vol. 74, Advances in Ceramic-Matrix Composites III. Edited by N.P. Bansal and J.P. Singh. American Ceramic Society, Westerville, OH, 1996. pp. 17-26.

\footnotetext{
- This approximation was based on the cost to fabricate 8-ply woven ( 5 harness satin) 6 in. $x 9$ in. plates of MI and CVI SiC composites. For example, the cost of a composite plate fabricated with HN fibers is $\$ 3500$ whereas the same plate fabricated with NIC or ZMI fibers would be $\$ 2300 .[10]$
} 
5. G.N. Morscher, "Tensile Stress Rupture of SiCf/SiCm Minicomposites with Carbon and Boron Nitride Interphases at Elevated Temperatures in Air," $J$. Am. Ceram. Soc., 80 [8] 2029-42 (1997)

6. G.N. Morscher, "The Effect of Static and Cyclic Tensile Stress and Temperature on Failure for Precracked Hi-Nicalon/BN/CVD SiC Minicomposites in Air," Ceram. Eng. Sci. Proc., 18 [3] 737-745 (1997)

7. K. Kumagawa, H. Yamaoka, M. Shibuya, and T. Yamamura, "Thermal Stability and Chemical Corrosion Resistance of Newly Developed Continuous SiZr-C-O Tyranno Fiber," Ceram. Eng. Sci. Proc. 18 [3] 113-118 (1997)

8. G.N. Morscher and J. Martinez-Fernandez, "Fiber Effects on Minicomposite Mechanical Properties for Several Silicon Carbide FiberChemically Vapor-Infiltrated Silicon Carbide Matrix Systems," J. Am. Ceram. Soc. in print (1999)

9. G.N. Morscher, D.R. Bryant, and R.E. Tressler, "Environmental Durability of BN-Based Interphases (for $\mathrm{SiCf} / \mathrm{SiCm}$ Composites) in $\mathrm{H} 2 \mathrm{O}$ Containing Atmospheres at Intermediate Temperatures," Ceram. Eng. Sci. Proc., 18 [3] 525-533 (1997)

10. J. Halada, private communication, Allied-Signal Composites Inc. 